\title{
Puddled or Forged? A Steel Bar in The Cathedral of Mexico, from the XVIII Century
}

\author{
M. E., Noguez*, D. Mojica*, R. Sánchez**, T. Robert* \\ * Facultad de Química, Departamento de Ingeniería Metalúrgica, Universidad Nacional Autónoma \\ de México, D. F., 04510 México, \\ * Instituto de Ingeniería, Universidad Nacional Autónoma de México, D. F., 04510 México.
}

The building of the Cathedral of Mexico began in 1616 and finished in 1813. From 1787 to 1791 the rising of the east tower was made with stone globes and cruises, Fig. 1 a) and b). A metallic bar was introduced, lowering from the center of the globe to the crosspiece of cedar vanes inside the tower, Fig. 2. During the restoration works, a small segment from this bar was cut (about $5-5.3 \mathrm{~cm}$ diameter and 0.5-0.8 cm thickness), Fig. 3, and analyzed. Chemical analysis, hardness tests and optical and electrical microscopy were used. There are two ways of knowing the origin of this bar: historically and by laboratory evidences.

From history, it is known that this bar was imported either from Spain or England, because steel making in Mexico began in 1807 [1]. The main iron and steel processes in that time was Catalan forge in Spain and puddled iron in England. Catalan forging used charcoal, wood and iron ores. The iron balls formed contained slags mixed with iron; the balls were struck, slags melted and were eliminated when the mass was forged producing billets, tools, bars, etc.; rolling is not mentioned in this process [2]. In England, for puddeling, metallurgists used mineral carbon (anthracite) as fuel. Slags melted while the steel remained in masses, the very spongy masses were taken to a hydraulic hammer for welding. Then, some of these bars were accommodated side by side for another hot rolling for welding them into a single material. In this way, the slag particles were elongated and distributed in the steel [2]. Considering that Mexico was under the rule of Spain it is probable that the bar was Spanish but, in that time with the enthusiasm of a new process, the bar could be brought from England [3].

From laboratory observations the following characteristics are indicated. The length of the bar is $469 \mathrm{~cm}$, with a very homogeneous diameter, unless the end, where the sample was cut. The head of the bar was definitely forged to a larger diameter, Fig. 4. The sample cut from the bar had indications of having being struck, with a small oxidation and fractures apparently produced by union by the masses near the center. The chemical composition was determined by an Emission spectroscopy, Spectro M-8; the average analysis is: $0.229 \%$ C, $0.126 \%$ Si, $0.027 \%$ Mn, $0.002 \%$ P, $0.006 \%$ S, $0.206 \% \mathrm{Cu}$, Fe bal. Moreno Revilla [4] reported that puddled iron have an average of $0.47 \% \mathrm{P}$ and $0.20 \% \mathrm{Si}$, while forged steels have $0.03 \% \mathrm{Si}$ and $0.08 \% \mathrm{P}$, therefore the above analysis is not conclusive for any process. Hardness tests show different values, indicating at least two microstructures, Fig. 5. Optical microscopy analysis shows at least two different carbon content steels, Fig. 6, this condition has been reported by Picasso et al. [5] as characteristic of puddle steel. Besides, it can be seen silicate inclusions in the transversal section, Fig. 8, corresponding to the rolling direction. This evidence points in the direction of puddle rolled steel.

A definite conclusion is not attained because both processes show similar characteristics; nevertheless the main differences are the fuel and the mechanical processes. A broader analysis is limited by the size of the sample. The bar, from which this sample was taken, was reintroduced into the Cathedral.

References

[1] Uribe S., Asclepio, Revista de Historia de la Medicina y de la Ciencia, 2006, Vol. LVIII, No. 2, July-December, ISSN: 0210-4466.

[2] Apraiz B., Fabricación de hierro, aceros y fundiciones, Ed. Urmo, S. A. de Ediciones, 1975.

[3] Vicuña, G., Revista Europea, Num. 44, 27 December 1874. 
[4] Moreno R. Jesús, PhD Thesis, Integridad estructural de vigas roblonadas de acero estructural antiguo, Departamento de Ciencia de los Materiales, Universidad Politécnica de Madrid, 2005.

[5] Picasso A., Romero R. and Cuniberti A., Jornadas SAM 2000, IV Coloquio Latinoamericano de Fractura y Fatiga, August 2000.

Acknowledgements to: Guillermina González M.

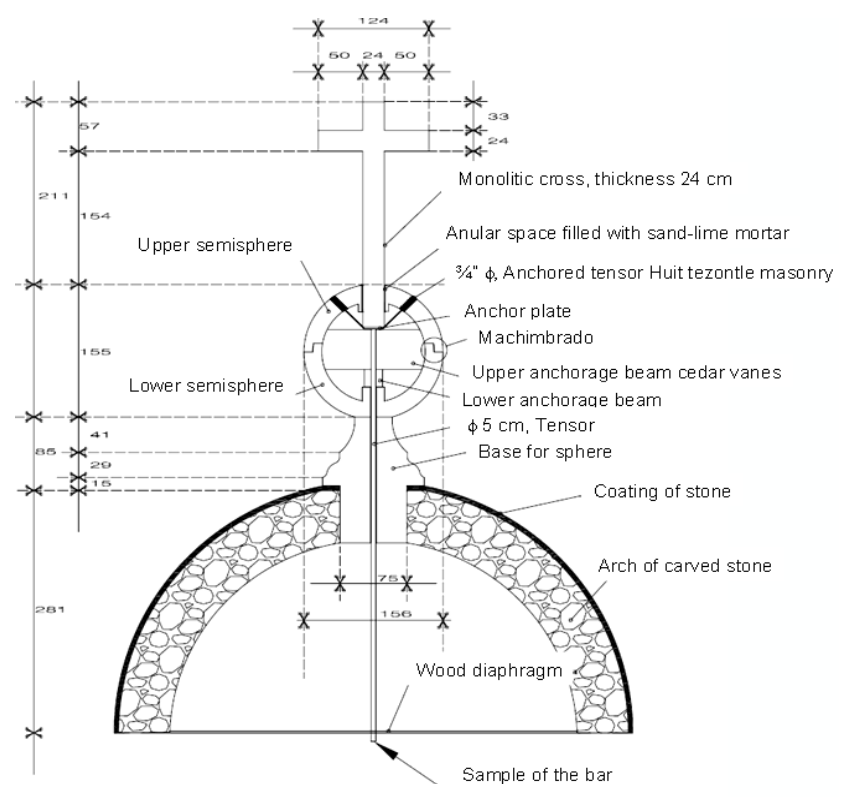

FIG.1. a) Diagram of the tower.
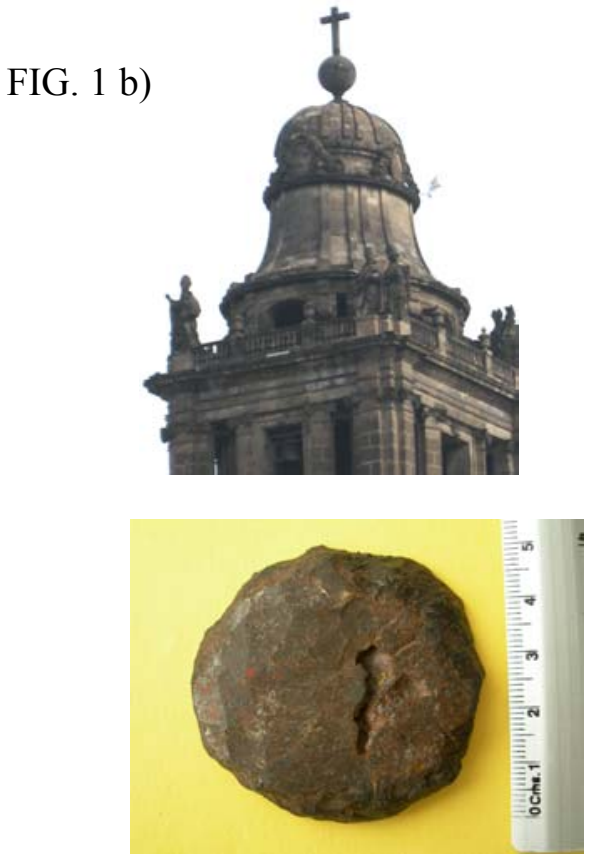

FIG. 2. Sample cut from the bar.

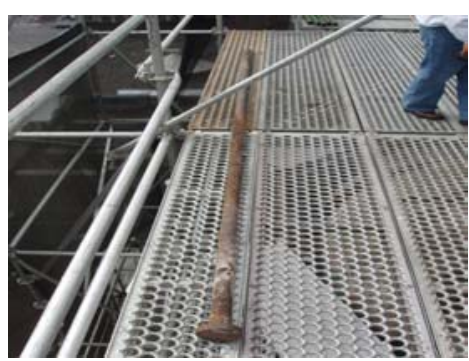

FIG. 3. Holding bar.

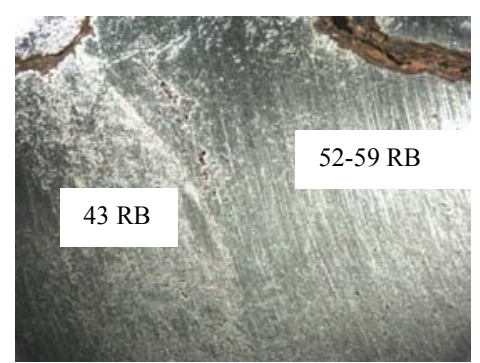

FIG. 4 Different hardness in the bar.

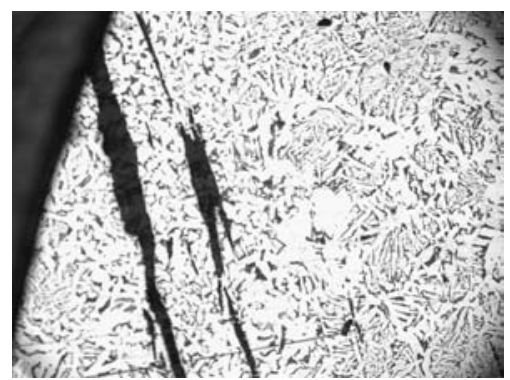

FIG. 7. Oriented aligned silicates. $100 \mathrm{X}$

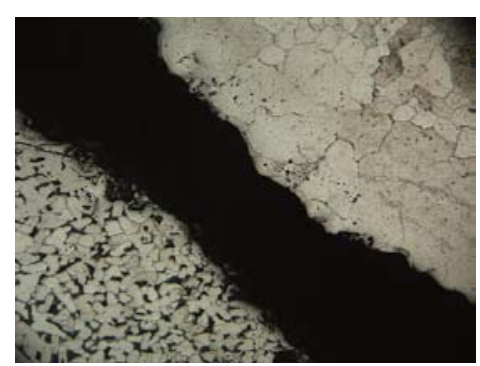

FIG. 5. Different microstructures,. $100 \mathrm{X}$

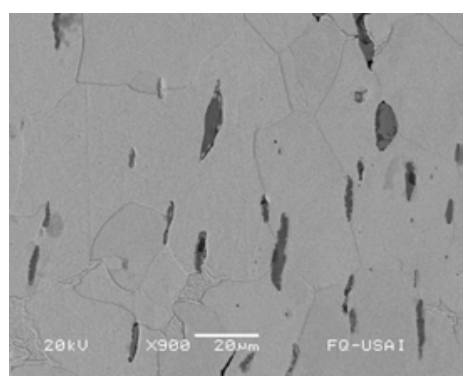

FIG. 8. Aligned silicates, SEM. $100 \mathrm{X}$ 